\title{
Rotina laboral e significados de qualidade de vida atribuídos por profissionais de Educação Física atuantes em academias de ginástica
}

\author{
Labor routine and quality of life meanings attributed by Physical Education professionals \\ working in fitness centers
}

Rutina laboral y significados de calidad de vida atribuido por profesionales de educación física que actúan en gimnasios

Danielle Pacheco Rebello, Alan Camargo Silva ${ }^{\mathrm{II}}$, Sílvia Maria Agatti Lüdorf III

\begin{abstract}
Resumo
O objetivo deste estudo foi analisar como os profissionais de Educação Física percebem sua qualidade de vida em relação ao trabalho realizado em academias de ginástica. Foi realizado um estudo de caso, com a aplicação de questionários a profissionais de Educação Física de uma academia de médio porte do Rio de Janeiro. Os resultados indicam que os profissionais acreditam ter uma qualidade de vida satisfatória. Contudo, o trabalho na academia de ginástica repercute de forma negativa na qualidade de vida, pois gera cansaço excessivo, ao ter que participar das aulas e trabalhar em mais de um lugar, além de não ser adequadamente remunerado.
\end{abstract}

Palavras-chave: Educação Física e treinamento; Docentes; Qualidade de vida

\begin{abstract}
The aim of this study was to analyze how Physical Education professionals notice their quality of life in relation to the work done in fitness centers. A case study was carried out with the application of questionnaires to Physical Education professionals from one medium-sized of Rio de Janeiro city, Brazil. In the results indicate that professionals believe they have a satisfactory quality of life. However, the routine in a fitness center decreases the quality of life because it generates excessive tiredness and because of their participation in classes and work in more than one place with low pay.
\end{abstract}

Keywords: Physical Education and training; Educators; Quality of life

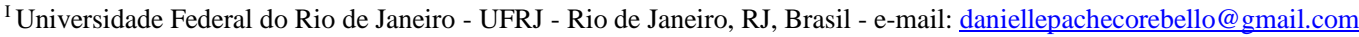

II Universidade Federal do Rio de Janeiro - UFRJ - Rio de Janeiro, RJ, Brasil - Endereço: Avenida Carlos Chagas Filho, 540 - Ilha do Fundão - Cidade Universitária, Rio de Janeiro, RJ, Brasil - CEP: 21941-598 - e-mail: alan10@ zipmail.com.br

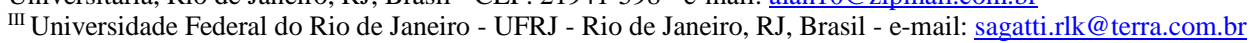




\section{Resumen}

El objetivo del estudio fue analizar como los profesionales de Educación Física aperciben su calidad de vida con relación al trabajo realizado en gimnasios. Por medio de un estudio de caso, se aplicaron cuestionarios a los profesionales que actúan en un gimnasio en Rio de Janeiro, Brasil. Los resultados indican que los profesionales creen tener una calidad de vida satisfactoria. Sin embargo, la rutina contribuye para la disminución de la calidad de vida por la participación de ellos en las clases, el trabajo en varios locales y la remuneración inadecuada.

Palavras clave: Educación Física y entrenamiento; Docentes; Calidad de vida

\section{Introdução}

A noção "qualidade de vida" emergiu pela primeira vez na literatura médica no início do século XX. Entretanto foi apenas nos anos de 1970 e 1980 que o conceito ganhou relevância no cenário acadêmico aparecendo como foco de pesquisa (MINAYO; HARTZ; BUSS, 2000; SEIDL; ZANNON, 2004; GORDIA et al., 2011). Investigações sobre qualidade de vida especificamente em relação ao trabalhador potencializam-se nessa época pela alta competitividade do mercado de trabalho cada vez mais exigente por profissionais qualificados (FORNO; FINGER, 2015).

Embora haja diversas definições de qualidade de vida no campo da Saúde, não existe consenso em torno do que signifique. Por ser um termo polissêmico ou ambíguo apresentando variações a depender do interlocutor, agrega muitas variáveis ao seu significado (MINAYO; HARTZ; BUSS, 2000; SEIDL; ZANNON, 2004; TAVARES, 2011; PEREIRA; TEIXEIRA; SANTOS, 2012). Em termos gerais, de acordo com o glossário temático sobre promoção da saúde do Ministério da Saúde, qualidade de vida pode ser considerada o "[...] grau de satisfação das necessidades da vida humana - como alimentação, acesso a água potável, habitação, trabalho, educação, saúde, lazer e elementos materiais - que tem como referência noções subjetivas de conforto, bem-estar e realização individual e coletiva" (p. 29).

Relações entre qualidade de vida e condições de trabalho são objeto de interesse de algumas áreas (HIPÓLITO et al., 2017; CAVALCANTE et al., 2018) cujos estudos normalmente são desenvolvidos pela abordagem quantitativa em uma perspectiva biológica. Contudo, é importante considerar as especificidades de atuação profissional, no presente caso, voltadas à intervenção em Educação Física.

Pesquisas sobre qualidade de vida na área de Educação Física vêm se desenvolvendo ao longo dos últimos anos. Essas pesquisas começaram na segunda metade do século $\mathrm{XX}$, período em que historicamente ocorreu o início dos programas governamentais de incentivo ao esporte (ALMEIDA; GUTIERREZ; MARQUES, 2009). Além de investigações sobre praticantes de atividade física, os profissionais que as orientam também vêm sendo objeto de análise em relação à qualidade de vida, dadas as particularidades relacionadas aos diferentes âmbitos de atuação em Educação Física, como escolas e academias de ginástica. 
Estudos voltados aos professores de Educação Física escolar apontam que a baixa remuneração, as condições insalubres de trabalho e o desequilíbrio de tempo entre a vida pessoal e profissional parecem ser os principais aspectos comprometedores da qualidade de vida desses docentes (LEMOS; NASCIMENTO; BORGATTO, 2007; FOLLE et al., 2008; BOTH et al., 2010; MOREIRA et al., 2010; NASCIMENTO et al., 2016). Já em pesquisas direcionadas à academia de ginástica, detectou-se a necessidade de o profissional de Educação Física trabalhar em mais de um local com uma alta carga horária semanal e uma sobrecarga laboral que impacta diretamente em seu corpo. Essa realidade dificultaria a adoção de hábitos ditos "saudáveis" em função da longa jornada de trabalho que são os principais aspectos que influenciam negativamente a qualidade de vida desses profissionais (ESPÍRITOSANTO; MOURÃO, 2005; PALMA et al., 2007; MILANO; PALMA; ASSIS, 2007; QUELHAS, 2012; BEVILACQUA et al., 2014; PALMA, 2014).

Entretanto poucos são os estudos que referenciam a qualidade de vida levando em consideração as condições de trabalho e o cotidiano dos profissionais de Educação Física. Assim, tendo em vista a escassez de estudos na área, é imperioso que se avance na compreensão sobre a situação laboral e qualidade de vida dos profissionais, o seu cotidiano e as condições de vida, especialmente no âmbito de academias de ginástica.

Argumenta-se sobre a importância de cada vez mais empreender estudos que explorem a qualidade de vida no e do trabalho (LACAZ, 2009; FORNO; FINGER, 2015). Nesse sentido, tal empreendimento de investigação pode indicar eventuais relações entre o processo de trabalho e a qualidade de vida dos próprios profissionais de Educação Física, o que repercute direta ou indiretamente nas suas atuações e/ou carreiras a curto, médio e longo prazo. Além disso, avançar no conhecimento de alguns aspectos dessa realidade pode proporcionar reflexões no âmbito da formação de profissionais e de associações científicas ou regulamentadoras, preocupadas com o labor desenvolvido no âmbito da Educação Física.

Assim, o objetivo deste estudo foi analisar os significados atribuídos ao trabalho em academias de ginástica e à qualidade de vida pelos profissionais de Educação Física e de que formas podem repercutir em suas atuações laborais ${ }^{1}$.

\section{Procedimentos metodológicos}

Este trabalho foi pautado pela abordagem qualitativa que tem como preocupação estudar determinado fenômeno a fim de entender seu significado individual e coletivo para as pessoas (TURATO,

\footnotetext{
${ }^{1}$ Este estudo é derivado de um Trabalho de Conclusão de Curso da Pós-Graduação Lato sensu em Treinamento Desportivo desenvolvido na Escola de Educação Física e Desportos da Universidade Federal do Rio de Janeiro (EEFD-UFRJ)
} 
2011). Mais precisamente, calcou-se no tipo de pesquisa denominado estudo de caso de caráter interpretativo (THOMAS; NELSON; SILVERMAN, 2012).

A pesquisa foi realizada no ano de 2016 em uma academia carioca de médio porte localizada no bairro do Engenho de Dentro, fundada há aproximadamente 30 anos por uma família. Segundo Bertevello (2006), uma academia é considerada de médio porte por ter um caráter familiar, e que opera com aproximadamente 15 professores empregados, podendo ter outros credenciados por contrato. $\mathrm{O}$ bairro de Engenho de Dentro onde fica localizada a academia é considerado de classe média, com um Índice de Desenvolvimento Humano de 0,857 , segundo dados do $\mathrm{IBGE}^{2}$. A incursão ao campo de pesquisa foi realizada por meio de autorização obtida junto aos gerentes que aceitaram o desenvolvimento da pesquisa com os profissionais do estabelecimento.

Essa academia assumia como "missão da empresa" promover saúde, qualidade de vida e bem estar para os alunos, ou ainda, ajudá-los da melhor maneira possível ao estabelecer um ambiente agradável para socialização a fim de facilitar a prática corporal de forma "leve" e "fácil". A academia climatizada com ar condicionado oferecia atividades de natação, hidroginástica, musculação, ciclismo indoor, ginástica localizada, treinamento funcional, jump, hiphop e jazz. A mensalidade da academia custava em média R\$ 150,00 e atendia aproximadamente 1000 alunos em um espaço de 1000 metros quadrados entre $6 \mathrm{~h}$ e 22h, oferecendo alguns horários promocionais (turno da tarde até às $16 \mathrm{~h}$ ou turno da noite a partir de $21 \mathrm{~h}$ ). $\mathrm{O}$ estabelecimento não fazia parte de uma rede de academias (filial) e possuía parcerias com outras empresas locais a fim de gerar "benefícios" aos residentes das redondezas como, por exemplo, descontos na mensalidade ou nos serviços (avaliação corporal, fisioterapia estética, hidroterapia, massagem equilibradora, nutrição e personal trainer).

Os critérios para a seleção dos sujeitos foram: ser formado em bacharelado ou licenciatura plena em Educação Física e trabalhar há, pelo menos, um ano em academias, para que o profissional tenha experiências laborais e do cotidiano suficientes para participar do estudo. Foram selecionados 26 profissionais, no entanto, 19 participaram do estudo, sete homens e 12 mulheres na faixa etária entre 25 e 59 anos, ganhando entre R\$2900,00 e R\$ 7249,99, conforme Quadro 1.

Quadro 1: Perfil dos profissionais de Educação Física

\begin{tabular}{cccc}
\hline Identificação & Idade & Sexo & Faixa Salarial (Salário Mínimo) \\
\hline P1 & 29 & M & 4 a 10 \\
P2 & 38 & M & até 2 \\
P3 & 29 & F & 2 a 4 \\
P4 & 47 & F & 4 a 10 \\
P5 & 38 & F & 4 a 10 \\
\hline
\end{tabular}

2 Este índice mensura o grau de desenvolvimento econômico e a qualidade de vida oferecida à população local. Disponível em: http://www.wikirio.com.br/IDH dos bairros da cidade do Rio de Janeiro. 


\begin{tabular}{llcc}
\hline P6 & 38 & F & até 2 \\
P7 & 44 & M & 2 a 4 \\
P8 & 36 & F & 2 a 4 \\
P9 & 31 & F & 2 a 4 \\
P10 & 42 & F & até 2 \\
P11 & 59 & F & 2 a 4 \\
P12 & 25 & M & 2 a 4 \\
P13 & 34 & M & 2 a 4 \\
P14 & 26 & F & até 2 \\
P15 & 29 & M & 2 a 4 \\
P16 & 47 & F & - \\
P17 & 41 & M & 2 a 4 \\
P18 & 35 & F & 2 a 4 \\
P19 & 37 & F & até 2 \\
\hline
\end{tabular}

Fonte: Dados originais da pesquisa.

Utilizou-se um questionário com perguntas abertas para a coleta de dados. O questionário foi composto de dois blocos de perguntas: o primeiro com questões voltadas ao perfil do pesquisado e o segundo constituído de oito perguntas relativas ao trabalho e à qualidade de vida do profissional de Educação Física: 1) Como é a sua rotina de trabalho diária no(s) local(is) em que atua como profissional de Educação Física?; 2) Quando pensou em realizar a graduação em Educação Física, imaginava que sua rotina de trabalho seria da forma que é atualmente? Comente um pouco a respeito.; 3) Você participa ativamente das aulas em que ministra? Comente um pouco acerca do assunto, explicando como interage com os alunos.; 4) Comparando sua faixa salarial mensal com o seu atual padrão de vida, o que você pensa a respeito?; 5) Descreva como é seu deslocamento diário para ir e vir do(s) trabalho(s) (meio de transporte, tempo médio, locais); 6) Descreva como você se sente ao final de uma semana de trabalho.; 7) Que tipos cuidados com você, adota ao longo da semana? Considera suficiente?; 8) Para você, o que é qualidade de vida? E como você definiria a sua qualidade de vida?

Optou-se por tal técnica de pesquisa pelo fato do questionário alcançar um maior número de pessoas em um curto espaço de tempo, além de permitir os pesquisados responderem com calma e de forma espontânea, sem se sentirem desaprovados em suas opiniões (GOLDENBERG, 2004). Primeiramente, foi realizada uma pesquisa piloto com alguns profissionais de Educação Física de outros estabelecimentos com o intuito de verificar a adequação das questões aos objetivos, alinhando-se, assim, às orientações de Minayo (2010) sobre a possibilidade de realizar pré-teste em roteiros em uma fase da pesquisa denominada de "exploratória".

Em termos éticos, preservando o sigilo das informações e o anonimato dos sujeitos, a pesquisadora esclareceu aos informantes que poderiam deixar o questionário respondido na recepção da academia a qualquer momento sem a sua presença. Tal estratégia foi fundamental na medida em que 
muitos estavam ocupados no momento e preferiam responder no intervalo das aulas ou pelo possível receio de que as informações fornecidas deixassem de ser anônimas.

O tratamento dos dados foi feito com base na análise de conteúdo de Turato (2011) no qual organiza os dados a partir de dois critérios para a construção de categorias: repetição e relevância. O primeiro se refere à intensidade com que uma informação aparece no material empírico e o segundo, a pontos que revelam aspectos importantes diante da proposta de estudo, não necessariamente atrelados à repetição.

\section{Apresentação e discussão dos resultados}

Os profissionais de Educação Física investigados apresentavam algumas características semelhantes associadas ao cotidiano laboral em academias de ginástica, dentre as quais cabe destacar: trabalhavam em dois ou mais lugares concomitantemente, possuíam carga horária de trabalho elevada e, não raro, ministravam várias aulas práticas durante o dia, junto aos alunos. Essas peculiaridades associadas a este campo de atuação auxiliam a compreender os significados de qualidade de vida e as relações com o trabalho, como será visto.

Os profissionais de Educação Física dessa academia ao tratarem sobre trabalho se remeteram à qualidade de vida, à rotina laboral, à participação deles nas aulas, ao cansaço diário, à crítica ao salário e aos cuidados com o corpo. As categorias supracitadas serão apresentadas e discutidas a seguir:

Em primeiro lugar, foi possível detectar como o profissional de Educação Física compreendia especificamente a sua própria qualidade de vida. As principais respostas para definir a qualidade de vida foram: trabalhar com o que gosta, tempo para lazer e tempo para a família:

\footnotetext{
Dormir ao menos 8 horas por noite, conseguir passar mais tempo com a família e conseguir gastar menos tempo no trânsito. (P3)

Qualidade de vida é ser feliz trabalhando com o que gosta, procurar se alimentar bem, ter tempo de lazer. (P5)

Hoje posso dizer que tenho qualidade de vida, pois moro perto do trabalho e participo constantemente da minha família e juntamente do crescimento das minhas filhas. (P7)

Qualidade de vida envolve fatores com trabalhar com o que gosta, ser feliz na profissão que escolheu, poder aproveitar os prazeres da vida como o convívio com os familiares. (P14)
}

Em termos gerais, para esses profissionais, qualidade de vida está essencialmente ligada a ter tempo para lazer e tempo para família. Mesmo trabalhando com o que gosta, é necessária a realização de outras atividades, muitas vezes fora do ambiente de trabalho. A carga horária elevada ou o cansaço 
apresentado podem ser as causas de não conseguirem passar mais tempo com a família. Por um lado, o trabalho pode ser um dos elementos que gera relativa satisfação do profissional em seu cotidiano diário. Estar satisfeito na profissão que escolheu estaria diretamente ligado à sua qualidade de vida. Entretanto, quando as condições de trabalho são precárias ou o profissional se vê obrigado a exercer certa tarefa por necessidade e/ou o salário não corresponde às expectativas, a carga laboral pode se tornar desagradável (PALMA, 2014).

Vale considerar também que, aparentemente, tais profissionais conseguem distinguir a noção de qualidade de vida da saúde propriamente dita uma vez que não houve relatos dicotômicos ou reducionistas relacionados a doenças ou a outros mal-estares, por exemplo. Esse dado alinha-se a uma visão crítica e ampliada sobre a noção de qualidade de vida e saúde (MINAYO; HARTZ; BUSS, 2000; SEIDL; ZANNON, 2004).

Em outras palavras, foi possível observar que a maioria dos profissionais de Educação Física assume que a qualidade de vida deles é "boa", ainda que com pouco tempo para cuidar da própria saúde, para o lazer ou estar com a família. Santos et al. (2013) afirmam que "Percebe-se que os professores de educação física de academias de ginástica apresentam uma qualidade de vida relativamente boa” (p. 230).

Destaca-se que a questão da qualidade de vida para o profissional de Educação Física não se reduz apenas ao sujeito que trabalha na área. Neste estudo, ainda que a percepção de qualidade de vida esteja atrelada àqueles que lidam com as práticas corporais nas academias de ginástica, destaca-se que todos ao redor dos profissionais podem ser afetados a depender de como concebem e vivenciam a sua rotina laboral cotidiana.

Cabe ressaltar que sete sujeitos não puderam participar da pesquisa por motivos diversos, tais como: incompatibilidade de horários, falta de tempo, etc.; o que, de certo modo, demonstrou indícios da rotina de trabalho e como isso poderia interferir na qualidade de vida desses profissionais. Esse dado pode indicar que a presente pesquisa investigou apenas professores de Educação Física que, provavelmente, ainda estão engajados na prática laboral já que muitos afetados pela síndrome do esgotamento profissional abandonam a profissão ou, por más condições de saúde, não conseguem continuar ativos no mercado de trabalho seja por desânimo, insatisfação ou falta de motivação com seus ofícios na área (GUEDES; GASPAR, 2016).

A categoria rotina foi elaborada a partir do que os profissionais relataram sobre os locais de trabalho, as descrições acerca do tempo de percurso e de seus deslocamentos no/pelo bairro/cidade por meio de transportes: 
Grandes deslocamentos dos locais de trabalho, e atualmente minha rotina de trabalho não é estressante, minha carga horária diária é menor, aumentei meus descansos entre os horários, mas em compensação reduzi meu salário.

(P6)

Segundas, quartas e sextas - estabelecimento 1: 06:00 - 12:00 / 15:30 - 17:30; estabelecimento 2 18:20 - 21:10. Terças e quintas: estabelecimento 1 09:00 - 12:00 / 17:00 - 21:00. (P12)

Rotina cansativa, acordo cedo, acumulo tarefas por ser dedicada, e fecho o dia tarde já que preciso somar horas de trabalho para melhorar a renda. (P14)

Grande parte dos profissionais de Educação Física trabalhava em dois ou mais lugares e apenas alguns dos sujeitos sinalizaram que a rotina de trabalho era "tranquila" ou "normal". A maioria deles demorava entre dez a 30 minutos para chegar ao trabalho, utilizando carro, bicicleta ou indo à pé. Quase todos os profissionais consideraram suas rotinas de trabalho diário cansativas. Foi possível detectar que tal realidade era mais pela alta carga horária de aulas na semana do que propriamente por causa dos seus deslocamentos entre residência e local de trabalho ou vice-versa. Mendes e Azevêdo (2014) observaram que dos professores entrevistados, o tempo médio que levavam em seus deslocamentos era de 30 minutos e que 54,7\% possuíam em média dois empregos. Já Espírito-Santo e Mourão (2005) detectaram que a média era de três ou mais lugares.

Ainda que seja uma academia de cunho "familiar" e que aparentemente não compete diretamente com os estabelecimentos de maior porte das redondezas, os profissionais de Educação Física parecem ainda sofrer cansaços físico-emocionais durante o trabalho, igualmente visto em outros estudos sobre carreira de quem atua na área do fitness (FREITAS et al., 2014; SILVA; FERREIRA, 2017; ANTUNES; LÜDORF; COELHO FILHO, 2017). Em outras palavras, a rotina do profissional e a qualidade de vida parecem ficar mais comprometidas com o tempo que tem que se dedicar ao estabelecimento.

Ao serem questionados se quando concluíram a graduação imaginavam que teriam essa sobrecarga laboral, parte dos profissionais esperava tal demanda de trabalho, mas outros não:

Não. Imaginei que conseguiria trabalhar um pouco menos e em menos lugares. (P3)

Sim. A rotina de um professor, principalmente de academia é muito "puxada". Temos que trabalhar bastante para conseguir um salário um pouco melhor. (P10)

Independentemente do perfil etário e do tipo de aula que ministravam, foi possível identificar, em termos gerais, que quase todos os pesquisados se queixaram acerca da quantidade de horas trabalhadas na semana. Essa realidade demonstra que não necessariamente o perfil da academia (tipo familiar ou filial) pode impactar na qualidade de vida dos profissionais, mas também a forma com que eles interagem com 
seus locais de trabalho para angariar lucros financeiros. Santos et al. (2013) verificaram que quanto maior o número de atividades laborais, maior a insatisfação e as consequências psicológicas negativas.

A participação nas aulas foi também uma das preocupações registradas pelos profissionais quando refletiram sobre o seu processo de trabalho:

Busco mostrar nas aulas de natação como executar cada exercício proposto e nas aulas de hidro faço a maior parte da aula como forma de incentivo. (P3)

No salão de musculação não há tanta possibilidade de participar dos treinos, mas nas aulas coletivas eu costumo participar em alguns momentos como forma de estímulo, é que geralmente você é o "espelho" do seu aluno. (P6)

Demonstro os exercícios, faço alguns com os alunos e quando não estou fazendo, incentivo os alunos, orientando-os. (P16)

Não, pois como dou uma aula após a outra seria muito cansativo e fazendo com o aluno não iria corrigi-lo da melhor forma. (P18)

Praticamente todos os profissionais de Educação Física mencionaram que participam ativamente nas suas aulas. Para eles, participar ativamente com os alunos, seja por meio de incentivo verbal, ou até mesmo realizando a aula, é algo importante e essencial. O profissional de Educação Física sendo o "espelho para o aluno" faz com que seja praticamente obrigatório que realize as atividades junto com a turma, portando-se como incentivador. Ele passa a ser um exemplo para o aluno e isso, muitas vezes, faz com que ele se sinta na obrigação de realizar as aulas. Essa noção de profissional de Educação Física como modelo parece vir desde o momento da graduação (SILVA et al., 2009) e permanecer ou ter implicações durante o seu próprio envelhecimento para se manter na profissão (SILVA; LÜDORF, 2012).

Essa participação ativa do profissional de Educação Física em todas as suas aulas impacta na sua própria qualidade de vida. Além dessas atividades físicas "não planejadas", o profissional ainda tenta manter uma série de exercícios previamente pensados para cuidar da sua própria saúde. Toda essa energia gasta ao longo do dia pode acarretar em uma sobrecarga "física" significativa ao profissional.

Outro elemento apontado pelos profissionais foi a questão do cansaço acumulado ao se remeterem às suas sensações ao longo de uma semana de trabalho:

\author{
Muitas vezes cansaço físico. (P12) \\ Fico cansada físico e mental. (P14) \\ Completamente cansada fisicamente e mentalmente. (P18)
}

Praticamente todos os pesquisados apontaram que há uma espécie de esgotamento profissional que se estabelece ao longo da semana. Alguns afirmaram ficar "cansados" ou "muito cansados" e outros, 
"exaustos", apresentando fadigas pela rotina de trabalho. Poucos afirmaram que ficavam "bem" ou "realizados" profissionalmente. Um dado emblemático foi quando a pesquisada "P3" utilizou as seis linhas que estavam designadas como espaço para resposta, escrevendo em letras maiúsculas a palavra "EXAUSTA".

Trabalhar em dois ou mais lugares por dia, participar das aulas junto aos alunos, praticar atividade física, se deslocar de um local para o outro, dentre outras demandas sociais, parece influenciar na qualidade de vida desses profissionais de Educação Física (ESPÍRITO-SANTO; MOURÃO, 2005; BEVILACQUA et al., 2014; MENDES; AZEVÊDO, 2014). Para Hartwig et al. (2012), “A exposições a fatores de risco para a saúde como cobranças por rendimento, ausência de pausas e as próprias características das ocupações podem gerar transtornos psicofísicos, alterando o estilo de vida dos trabalhadores" (p. 507).

Outra preocupação apresentada pelos profissionais de Educação Física foi o salário. Esse dado emergiu significativamente quando foram estimulados a compararem a faixa salarial com o seu atual padrão de vida:

\footnotetext{
A hora/aula está muito defasada, você tem que trabalhar muito para conseguir um salário mensal razoável. (P8)

Meu salário não mantém o meu padrão de vida, apesar de trabalhar todos os dias da semana não recebo o suficiente para manter um filho e eu. (P9)
}

Quase todos os profissionais de Educação Física demonstraram insatisfação com o que ganham financeiramente. Os profissionais que participaram da pesquisa alegaram que ganhavam pouco ou que não recebiam o suficiente para manter seu padrão de vida e/ou sustentar sua família, mesmo cumprindo uma carga horária de trabalho diária elevada. Em relação ao padrão de vida, este pode ser influenciada pelo senso comum em que o dinheiro é o quantificador de saúde. Sendo assim, ter dinheiro, para esses profissionais, representaria estar bem de saúde e com boa qualidade de vida, como também observado por Silva e Lüdorf (2012).

A questão salarial é muito discutida na literatura e muitos autores também verificaram essa insatisfação em relação à remuneração dos profissionais de Educação Física, independente da área de atuação (PALMA et al. 2007; SILVA; NUNEZ, 2009; MOREIRA et al. 2010; MENDES; AZEVÊDO, 2014).

Diante desse contexto, os próprios profissionais de Educação Física apontaram preocupações em relação aos cuidados que possuem no que diz respeito ao corpo, tais como controle da alimentação, prática de atividade física e horas de sono: 
Procuro manter uma rotina de atividade física, boa noite de sono e boa alimentação, porém muitas vezes essa rotina não é possível. (P4)

Procuro dormir cedo. Me alimentar bem durante o dia e praticar atividades físicas durante a semana. (P6)

Por conta da grande carga horária semanal e do cansaço ao longo de um dia de trabalho, muitos profissionais relataram que não conseguem manter essa rotina de atividades, ainda que apontassem os cuidados que teoricamente deveriam tomar. Esses cuidados são concebidos como importantes pelos profissionais de Educação Física, pois estão diretamente relacionados ao que tange o lado físico da qualidade de vida.

Assim, os profissionais de Educação Física acabam ficando à mercê de suas condições de trabalho, pois, ao cuidarem dos seus alunos, comprometem a sua própria "saúde e qualidade de vida" (MENDES; AZEVÊDO, 2014). As horas de sono, por exemplo, são consideradas pelos pesquisados importantes para manter uma boa qualidade de vida, porém, mesmo conscientes disso, a maioria não consegue dormir o necessário (ESPÍRITO-SANTO; MOURÃO, 2005; MILANO; PALMA; ASSIS, 2007). A prática de atividade física regular é uma das causas para a percepção da qualidade de vida como positiva (SILVA et al., 2016).

\section{Conclusões}

Foi possível analisar os significados atribuídos ao trabalho em academias de ginástica e à qualidade de vida pelos profissionais de Educação Física. Em termos gerais, o processo de trabalho em Educação Física interfere significativamente nas suas atuações e/ou carreiras profissionais, ou ainda, na qualidade de vida.

Os profissionais acreditam ter uma boa qualidade de vida. Entretanto, tais profissionais não consideram justa a remuneração que recebem e se queixam de estarem muito cansados ao fim de uma semana de trabalho. Também foi encontrado que, nesse grupo, mesmo trabalhando em dois ou mais lugares, a maioria gastava pouco tempo se deslocando entre os locais. Alimentação, atividade física e as horas de sono, são as principais preocupações quando se referem a cuidados com o próprio corpo. Para esses profissionais, qualidade de vida está diretamente ligado ao bem-estar físico e mental, ter tempo de lazer e tempo para a família. Os profissionais de Educação Física, portanto, percebem a qualidade de vida de uma forma global, caracterizando-a a partir da satisfação geral com a vida.

Embora ter investigado uma academia de ginástica e um público específico de profissionais de Educação Física, por meio de questionários, possam ser consideradas limitações deste estudo, cabe questionar em que medida tais relações microscópicas entre o trabalho e a qualidade de vida desses 
sujeitos extrapolam para outros locais ou âmbitos de trabalho (clube, escola, etc.). Tendo em vista a necessidade de se explorar essas e outras facetas relacionadas à qualidade de vida de profissionais de Educação Física, sugere-se a triangulação de outras técnicas de pesquisa, assim como, a comparação entre diferentes espaços laborais.

Nesse sentido, recomenda-se mais estudos que ampliem a coleta de dados, em especial, investigações que foquem em diferentes perfis de academias, ou ainda, que compreendam possíveis singularidades quanto às modalidades de práticas corporais oferecidas pelo estabelecimento. Assim, ao mesmo tempo em que se ampliaria a compreensão dos significados de qualidade de vida atribuídos pelos professores de Educação Física em diferentes realidades econômicas, sociais e culturais, seria possível detalhar as peculiaridades de se trabalhar em diferentes nichos profissionais (ginástica localizada, ciclismo indoor, atividades aquáticas, jump, etc.).

\section{Referências}

ALMEIDA, Marco Antonio Bettine de; GUTIERREZ, Gustavo Luis; MARQUES, Renato Francisco Rodrigues. Qualidade de vida como objeto de estudo polissêmico: contribuições da Educação Física e do Esporte. Revista Brasileira de Qualidade de Vida, Ponta Grossa, v. 1, n. 1, p. 15-22, 2009.

ANTUNES, Márcio Felipe Carelli; LÜDORF, Sílvia Maria Agatti; COELHO FILHO, Carlos Alberto de Andrade. $O$ trabalho do profissional de Educação Física com ginástica coletiva em academia. Educação em Foco, Juiz de Fora, v. 22, n. 1, p. 1-25, 2017.

BERTEVELLO, Gilberto. Academias de ginástica e condicionamento físico: desenvolvimento. In: DACOSTA, L. (Org.) Atlas do esporte no Brasil. Rio de Janeiro: CONFEF, 2006. p. 63-64.

BEVILACQUA, Lidiane Amanda et al. Qualidade de vida e satisfação com o trabalho de profissionais das academias de ginástica da cidade de Pelotas/RS. Revista Brasileira de Atividade Física e Saúde, Pelotas, v. 19, n. 3, p. 314-324, 2014.

BOTH, Jorge et al. Condições de vida do trabalhador docente: associação entre estilo de vida e qualidade de vida no trabalho de professores de Educação Física. Motricidade, Santa Maria da Feira, v. 6, n. 3, p. 39-51, 2010.

CAVALCANTE, Roberto Medeiros da Fonsêca et al. Qualidade de vida e qualidade de vida no trabalho: uma revisão bibliográfica. Revista Multidisciplinar e de Psicologia, v. 12, n. 40, 2018.

ESPÍRITO-SANTO, Giannina; MOURÃO, Ludmila. Saúde e trabalho: o caso das professoras de Educação Física que atuam em academias de ginástica no Rio de Janeiro. Corpus et Scientia, Rio de Janeiro, v. 1, n. 1, p. 41-47, 2005.

FOLLE, Alexandra et al. Carreira no magistério público e nível de qualidade de vida no trabalho docente em Educação Física. Motriz, Rio Claro, v. 14, n. 3, p. 210-221, 2008. 
FORNO, Cristiano Dal; FINGER, Igor da Rosa. Qualidade de vida no trabalho: conceito, histórico e relevância para a gestão de pessoas. Revista Brasileira de Qualidade de Vida, Ponta Grossa, v. 7, n. 2, p. 103-112, 2015.

FREITAS, Diego Costa et al. O envelhecer na visão do profissional de Educação Física atuante em academia de ginástica: corpo e profissão. Movimento, Porto Alegre, v. 20, n. 4, p. 1523-1541, 2014.

GOLDENBERG, Mirian. A arte de pesquisar: como fazer pesquisa qualitativa em ciências sociais. 8 ed., Rio de Janeiro: Record, 2004.

GORDIA, Alex Pinheiro et al. Qualidade de vida: contexto histórico, definição, avaliação e fatores associados. Revista Brasileira de Qualidade de Vida, Ponta Grossa, v. 3, n. 1, p. 40-52, 2011.

GUEDES, D.; GASPAR, E. "Burnout” em uma amostra de profissionais de Educação Física brasileiros. Revista Brasileira de Educação Física e Esporte, São Paulo, v. 30, n. 4, p. 999-1010, 2016.

HARTWIG, Tiago Wally et al. Condições de saúde de trabalhadores de academias da cidade de PelotasRS: um estudo de base populacional. Revista Brasileira de Atividade Física e Saúde, Pelotas, v. 17, n. 6, p. 500-511, 2012.

HIPÓLITO, Maiza Claudia Vilela et al. Qualidade de vida no trabalho: avaliação de estudos de intervenção. Revista Brasileira de Enfermagem, Brasília, v. 70, n. 1, p. 189-197, 2017.

LACAZ, Francisco Antonio de Castro. Qualidade de vida n(d)o trabalho: um conceito político e polissêmico. Trabalho, Educação e Saúde, Rio de Janeiro, v. 7, n. 3, p. 565-572, 2009.

LEMOS, Carlos Augusto Fogliarini; NASCIMENTO, Juarez Vieira do; BORGATTO, Adriano Ferreti. Parâmetros individuais e sócio-ambientais da qualidade de vida percebida na carreira docente em Educação Física. Revista brasileira de Educação Física e Esporte, São Paulo, v. 21, n. 2, p. 81-93, 2007.

MENDES, Alessandra Dias; AZEVÊDO, Paulo Henrique. O trabalho e a saúde do educador físico em academias: uma contradição no cerne da profissão. Revista brasileira de Educação Física e Esporte, São Paulo, v. 28, n. 4, p. 599-615, 2014.

MILANO, Fernanda; PALMA, Alexandre; ASSIS, Monique. Saúde e trabalho dos professores de Educação Física que atuam com ciclismo indoor. Revista Digital EFDeportes, Buenos Aires, v. 12, n. 109, 2007.

MINAYO, Maria Cecília de Souza; HARTZ, Zulmira Maria de Araújo; BUSS, Paulo Marchiori. Qualidade de vida e saúde: um debate necessário. Ciência \& Saúde Coletiva, Rio de Janeiro, v. 5, n. 1, p. 7-18, 2000.

MINAYO, Maria Cecília de Souza. O desafio do conhecimento: pesquisa qualitativa em saúde. 12. ed., São Paulo: Hucitec, 2010.

MOREIRA, Hudson de Resende et al. Qualidade de vida no trabalho e perfil do estilo de vida individual de professores de Educação Física ao longo da carreira docente. Motriz, Rio Claro, v. 16, n. 4, p. 900912, 2010. 
NASCIMENTO, Raquel Krapp et al. Job satisfaction among physical education teachers from the municipal network of São José-SC. Journal of Physical Education, Maringá, v. 27, e2740, 2016.

PALMA, Alexandre et al. Trabalho e saúde: o caso dos professores de Educação Física que atuam em academias de ginástica. Cadernos IPUB (UFRJ), Rio de Janeiro, v. 13, p. 11-30, 2007.

PALMA, Alexandre. E como segue a saúde dos professores de educação física? Corpus et Scientia, Rio de Janeiro, v. 10, n. 2, p.1-15, 2014.

PEREIRA, Érico Felden; TEIXEIRA, Clarissa Stefani; SANTOS, Anderlei dos. Qualidade de vida: abordagens, conceitos e avaliação. Revista brasileira de Educação Física e Esporte, São Paulo, v. 26, n. 2, p. 241-250, 2012.

QUELHAS, Álvaro de Azevedo. Trabalhadores de Educação Física no segmento fitness: um estudo da precarização do trabalho no Rio de Janeiro. 2012. 250 f. Tese (Doutorado em Ciências Sociais), Universidade Estadual Paulista, Marília, 2012.

SANTOS, José Diogo Andrade dos et al. Qualidade de vida dos professores de academia de ginástica da cidade de Olinda-Pernambuco. Revista da Educação Física/UEM, Maringá, v. 24, n. 2, p. 225-231, 2013.

SEIDL, Eliane Maria Fleury; ZANNON, Célia Maria Lana da Costa. Qualidade de vida e saúde: aspectos conceituais e metodológicos. Caderno de Saúde Pública, Rio de Janeiro, v. 20, n. 2. p. 580-588, 2004.

SILVA; Alan Camargo et al. A visão de corpo na perspectiva de graduandos em Educação Física: fragmentada ou integrada? Movimento, Porto Alegre, v. 15, n. 3, p. 109-126, 2009.

SILVA; Alan Camargo; LÜDORF, Sílvia Maria Agatti. Possíveis relações entre corpo, saúde e o envelhecimento do professor de Educação Física. Movimento, Porto Alegre, v. 18, n. 2, p. 187-204, 2012.

SILVA; Alan Camargo; FERREIRA, Jaqueline. Profissionais de Educação Física atuantes na musculação: a dor corporal como performance laboral. Journal of Physical Education, Maringá, v. 28, n. 1, 2017.

SILVA, Junior Vagner Pereira da; NUNEZ, Paulo Ricardo Martins. Qualidade de vida, perfil demográfico e profissional de professores de Educação Física. Pensar a Prática, Goiânia, v. 12, n. 2, p. $1-11,2009$.

SILVA, Patrick Leonardo Nogueira da et al. Avaliação da qualidade de vida de idosos praticantes de atividade física de uma unidade básica de saúde de Minas Gerais. Revista da Universidade Vale do Rio Verde, Três Corações, v. 14, n. 2, p. 24-35, 2016.

TAVARES, Frederico de Mello Brandão. Apontamentos sobre o conceito de qualidade de vida: revisões, cruzamentos e possibilidades críticas. Revista Brasileira de Qualidade de Vida, Ponta Grossa, v. 3, n. 2, p. 23-32, 2011. 
THOMAS, Jerry; NELSON, Jack; SILVERMAN, Stephen. Métodos de pesquisa em atividade física. 6. ed., Porto Alegre: Artmed, 2012.

TURATO, Egberto Ribeiro. Tratado da metodologia da pesquisa clínico-qualitativa: construção teórico-epistemológica, discussão comparada e aplicação nas áreas da saúde e humanas. 5. ed., Petrópolis: Vozes, 2011.

\section{Como citar este artigo}

REBELLO, Danielle Pacheco; SILVA, Alan Camargo; LÜDORF, Sílvia Maria Agatti. Rotina laboral e significados de qualidade de vida atribuídos por profissionais de Educação Física atuantes em academias de ginástica: um estudo qualitativo. Revista Kinesis, Santa Maria, v. 38, p.01-15, 2020. 